\title{
The effect of migration on social capital and depression among older adults in China
}

\author{
Qiuju $\mathrm{Li}^{1} \cdot$ Xudong $\mathrm{Zhou}^{1} \cdot \mathrm{Sha} \mathrm{Ma}^{1} \cdot \operatorname{Minmin} \mathrm{Jiang}^{1} \cdot \mathrm{Lu} \mathrm{Li}^{1}$
}

Received: 12 October 2016/Accepted: 15 June 2017/Published online: 15 September 2017

(c) The Author(s) 2017. This article is an open access publication

\begin{abstract}
Purpose An estimated 9 million elderly people accompanied their adult children to urban areas in China, raising concerns about their social capital and mental health following re-location. The aim of this study was to examine the effect of migration on social capital and depression among this population.

Methods Multistage stratified cluster sampling was applied to recruit the migrant and urban elderly in Hangzhou from May to August, 2013. Data were collected from face-toface interviews by trained college students using a standardized questionnaire. Social capital measurements included cognitive (generalized trust and reciprocity) and structure (support from individual and social contact) aspects. Depression was measured by Geriatric Depression Scale-30 (GDS-30). Chi-square tests and binary logistic regression models were used for analysis.

Results A total of 1248 migrant elderly and 1322 urban elderly were eligible for analysis. After adjusting for a range of confounder factors, binary logistic regression models revealed that migrant elderly reported significantly lower levels of generalized trust $[\mathrm{OR}=1.34,95 \% \mathrm{CI}$ $(1.10-1.64)], \quad$ reciprocity $\quad[\mathrm{OR}=1.55, \quad 95 \% \quad \mathrm{CI}$ (1.29-1.87)], support from individual [OR $=1.96,95 \% \mathrm{CI}$ (1.61-2.38)] and social contact $[\mathrm{OR}=3.27,95 \% \mathrm{CI}$ (2.70-3.97)]. In the full adjusted model, migrant elderly were more likely to be mentally unhealthy $[\mathrm{OR}=1.85$, 95\% CI (1.44-2.36)] compared with urban elderly.
\end{abstract}

$\mathrm{Lu} \mathrm{Li}$

lilu@zju.edu.cn

1 School of Medicine, The Institute of Social and Family Medicine, Zhejiang University, 866 Yuhangtang Rd, Hangzhou 310058, Zhejiang, People's Republic of China
Conclusions Migrant elderly suffered from a lower mental health status and social capital than their urban counterparts in the emigrating city. Attention should focus on improving the social capital and mental health of this growing population.

Keywords Migration · Elderly · Social capital · Depression · China

\section{Introduction}

A tragedy occurred in Nanjing, Jiangsu province, in March 2016. One rural-to-urban migrant elderly committed suicide after being depressive for failing to adapt to urban life [1]. This kind of elderly health problem appearing during the process of rapid social change is exactly what this research focuses on.

According to the 2010 census, there were 221 million rural-to-urban migrants in China (Statistics of the Fifth National Census in 2010). Since the early 1990s, one of the vital changes in migration patterns is from individual to family migration [2], with young children and aging parents joining migrant workers. An estimated $6 \%$ of all migrants (approximately 9 million individuals) were aged 60 years and over as of 2010, an increase of 871,000 since 2005 [3]. Further rapid increases have been predicted during this current decade due to the one child policy and an aging population [4].

As a new social phenomenon, these elderly migrants have received considerable public and political attention in recent years. Family factors, such as looking after grandchildren, were the main migration motivation of Chinese older adults, which is different with that of other migrants $[5,6]$. As older people move, they face drastic change on 
lifestyle and living environment, which have been reported by World Health Organization as main factors affecting health. Besides, older migrants face many challenges in adapting to the new environment, especially for the ruralto-urban migrant elderly. China's urban-rural dualistic structure has created a dual lifestyle and cultural belief. Specifically, China's household registration, Hukou system, which discriminates between urban residents and migrants, adds an additional welfare strain [7]. Restrictions on access to healthcare, employment, education, housing, and social insurance as local residents, leads to inequality of social capital and health. Such circumstances may increase risk of late-life depression, which has been identified as a leading cause of morbidity and mortality in older adults $[8,9]$.

Migration and migration-related processes have been widely found to increase risk for depression [10]. Existing literature in China has identified the huge impact of migration on the wellbeing of migrant workers and left behind elderly. The majority of studies reported that temporary rural-to-urban migrant workers have a higher risk of depression than their urban counterparts [11-14], and left behind elderly are more likely to be mentally unhealthy [15] and have lower social support [16, 17]. However, migrant elderly are less economically and physically able to overcome the negative effects of migration compared with younger migrants and may suffer more directly negative effect of migration than left behind elderly. These might seriously jeopardize the wellbeing of migrant elderly. Furthermore, researches to date focusing on the sizable elderly migrant population in China have been limited to studies concentrated on the characteristics of migration [4, 18, 19], and social adaptation [20], with no studies examining risk for depression.

Social capital—such as community involvement, trusted others, and a sense of belonging - is likely to play an important role in the adjustment to destination community for elderly migrants. Defined broadly as the features of social organization that can improve the efficacy of society by facilitating coordinated actions, social capital has been found to be strongly associated with physical and mental health among Chinese populations [21-24]. While the process of internal migration may be a threat to social capital [25], such as risks including for example social and linguistic isolation [26], robust social capital may also serve as a protective factor to well-being. Therefore, additional research is needed to clarify the relationships among social capital, depression, and migration of elderly people in the Chinese context.

In this study, we sought to explore the effect of migration on social capital and depression of migrant elderly by comparison with local urban elderly. The specific objectives of this study were to investigate whether there are differences in the prevalence of depression and social capital between migrant and urban elderly and to examine how migration-related depression might be mediated by social capital. We hypothesized that migrant elderly are more likely to be depressed and have lower social capital than urban elderly. We also expected that the relationship between migration and depression will be mediated by social capital.

\section{Methods}

\section{Participants and procedures}

A cross-sectional survey was conducted in Hangzhou between May and August 2013. Hangzhou is a relatively developed city in China, with an urban per capita GDP of $\$ 14,013$ USD in 2013 (compared with $\$ 15,000$ USD for developed countries in 2012). Migrant elderly were defined as individuals aged 60 years and over who have been living in Hangzhou for at least 3 months and do not have local residency status. Urban elderly, the counterparts of migrant elderly, were people who have been living in Hangzhou for at least 6 months and do hold local residency status.

Research participants were recruited by multistage stratified cluster sampling. For migrant elderly, two districts with high densities of immigrant populations (Yuhang and Binjiang) were selected from Hangzhou's total 13 districts as study sites, and one sub-district was randomly selected from each of these. Two communities were then randomly selected from each sub-district giving a total of four communities. Then local community leaders were asked to provide a complete list of migrant elderly living in each community. For the urban elderly, three districts (Xihu, Gongshu, and Yuhang) were randomly selected to, respectively, represent high, middle, and low level of urbanization. One sub-district was then randomly selected from each of the three districts, and two communities randomly selected from each of these to represent high or low development level. After that, local general practitioners were asked to provide a list of the names of the urban elderly living in each community according to the health files.

Participants aged 60 years and over, matching the inclusion criteria, willing to participate, and able to communicate in Mandarin Chinese, were invited to a face-toface interview by trained interviewers. The average length of the interview was $30 \mathrm{~min}$. Those who had cognitive impairment or diagnosis of dementia were excluded from this study. All the elderly were initially approached by local community leaders or general practitioners about their willingness to complete a questionnaire of social capital and health. Those that expressed willingness to 
participate were asked to come to community center to complete questionnaire. Informed consent was obtained from participants and ethical approval for the study had been gained from Zhejiang University Research Ethics Committee.

\section{Measures}

\section{Individual-level Social Capital}

Cognitive Social Capital was measured with by asking respondents to show extent of agreement with a series of statements about trust and reciprocity [27]. Trust in others was assessed with the following single item: "Generally speaking, can most people be trusted?". Responses to the question ranged from 'strongly agree' (scored 5) to 'strongly disagree' (scored 1). The scores of the trust in the analysis were dichotomized as high trust (trust $=4-5$ ) and low trust (trust $=1-3$ ). Reciprocity was assessed by four items adapted from the World Bank Social Capital Scale [28]. These items were: "In addition to concerning themselves with their own business, are neighbors in the village also concerned about other people's business and community matters?", "Villagers will provide help if someone really needs it", "I would lend money to my neighbor if he/ she needs it to see a doctor", and "I would like to support a project that might not benefit me most, but benefit other villagers". The validity and reliability of each question or statement have been assessed in China [27]. Response to each question ranged from 'strongly agree' (scored 5) to 'strongly disagree' (scored 1). Then the scores were summed up and dichotomized as high reciprocity if the sum score is at or above the mean and low reciprocity if otherwise.

Structural social capital was measured with items concerning social support and social contact. Social support from individuals was measured by the question "In the last 12 months, have you received any help or support that is emotional help, economic help or assistance in helping you know or do things?" Participants then indicated 'yes' (support received) or 'no' (support not received) for a range of sources (Family, Friends who are not neighbors, neighbors, government officials/civil service, community leaders, charitable organizations/NGO, religious leaders, politicians, and Other). Each source of help received generated a sum score which was categorized in the analysis as high support received (if sum score $\geq 1$ ), or low support received (responding to score 0). Social contact was assessed by the question "On average, how many times a week do you and others (family members, neighbors, friends, etc.) usually drop in on one another?" The answer was categorized as high social contact (if responding $\geq 1$ ) and low social contact (if responding to 0 ).

\section{Depression}

Depressive symptoms were measured by the 30 -item Geriatric Depression Scale (GDS-30), which has been widely used for the elderly worldwide [29]. The validity and reliability of GDS-30 have been extensively assessed in China [30, 31]. Respondents were asked 30 yes/no questions relating to symptoms of depression and anxiety experienced during the previous week. The sum score ranged from 0 to 30 . Those who reported 10 or fewer symptoms were considered normal, 11-20 symptoms were mildly depressed, and 21 or more symptoms were moderately to severely depressed [32]. The Cronbach's alpha coefficient of the GDS-30 was 0.86 for the entire sample, 0.84 for urban sample and 0.88 for migrant sample.

\section{Demographic characteristics}

Demographic characteristics, which were treated as covariates, included sex (Female, Male), age group (60-69, 70-79, 80-years), marital status (Married, Widowed, Other), living arrangement (Living with family member, Living alone), religious faith (Having, Not having) and physical function. Education level was categorized into "illiterate, primary school, junior high school, and senior high school and high". Annual household income (RMB) was divided into groups of $0-24,999,25,000-49,999$, $50,000-74,999$, and 75,000 or more.

\section{Statistical analysis}

Chi-square tests (for categorical variables) or ANOVA (for continuous variables) were first used to examine the difference of demographic variables, social capital, and depression among the two groups (migrant or urban). Binary logistic regression models were then conducted to investigate the difference in social capital and depression between the two elderly groups after adjusting for a range of potential cofounders, such as sex, age, educational level, marital status, living arrangement and others. Depression was tested according to three different models. The variable sets were entered stepwise in the following sequence: (1) sex, age, and migrant status; (2) educational level, marital status, household income, living arrangement, religious faith and physical function; and (3) support from individual, social contact, generalized trust and reciprocity. The odds ratios (OR), 95\% confidence intervals $(\mathrm{CI})$, and $p$ value were presented. Statistical significance was set at a $p$ value of less than 0.05 . All statistical analyses were performed using SPSS for Windows Version 23.0. 
Table 1 Socio-demographic characteristics of the participants $[N(\%)]$

\begin{tabular}{|c|c|c|c|c|}
\hline Variable & Urban elderly $(N=1322)$ & Migrant elderly $(N=1248)$ & $\chi^{2}$ or $t$ & $p$ \\
\hline $\operatorname{Sex}$ & & & 10.662 & 0.001 \\
\hline Male & $530(40.1)$ & $580(46.5)$ & & \\
\hline Female & $792(59.9)$ & $668(53.5)$ & & \\
\hline Age & & & 211.459 & 0.000 \\
\hline $60-69$ & $748(56.6)$ & $1007(80.7)$ & & \\
\hline $70-79$ & $356(26.9)$ & $208(16.7)$ & & \\
\hline $80-$ & $218(16.5)$ & $33(2.6)$ & & \\
\hline Marital status & & & 23.352 & 0.000 \\
\hline Married & 1015 (77.6) & $1031(82.6)$ & & \\
\hline Widowed & $264(20.2)$ & $170(13.6)$ & & \\
\hline Other & $29(2.2)$ & $47(3.8)$ & & \\
\hline Education level & & & 56.321 & 0.000 \\
\hline Illiteracy & $350(26.6)$ & $193(15.5)$ & & \\
\hline Primary school & $357(27.1)$ & $341(27.3)$ & & \\
\hline Junior high school & $337(25.6)$ & $354(28.4)$ & & \\
\hline Senior high school and high & $273(20.7)$ & $360(28.8)$ & & \\
\hline Annual household income (RMB) & & & 124.191 & 0.000 \\
\hline $0-24,999$ & $294(22.2)$ & $406(32.5)$ & & \\
\hline $25,000-49,999$ & $356(26.9)$ & $474(38.0)$ & & \\
\hline $50,000-74,999$ & 457 (34.6) & $231(18.5)$ & & \\
\hline $75,000-$ & $215(16.3)$ & $137(11.0)$ & & \\
\hline Living arrangement & & & 255.741 & 0.000 \\
\hline Living with family member & $908(68.7)$ & $1141(93.8)$ & & \\
\hline Living alone & $414(31.3)$ & $76(6.2)$ & & \\
\hline Religious faith & & & 0.050 & 0.823 \\
\hline Having & $376(28.4)$ & $350(28.0)$ & & \\
\hline Not having & 946 (71.6) & $898(72.0)$ & & \\
\hline Physical function (mean $\pm \mathrm{SD}$ ) & $81.7 \pm 21.1$ & $89.0 \pm 16.7$ & -9.811 & 0.000 \\
\hline Generalized trust & & & 4.990 & 0.025 \\
\hline Low & $910(69.0)$ & $911(73.0)$ & & \\
\hline High & 409 (31.0) & $337(27.0)$ & & \\
\hline Reciprocity & & & 7.905 & 0.005 \\
\hline Low (less than the mean) & $572(43.3)$ & $609(48.8)$ & & \\
\hline High (above the mean) & $750(56.7)$ & $639(51.2)$ & & \\
\hline Support from individual & & & 42.756 & 0.000 \\
\hline Low $($ sum score $=0$ ) & $378(28.6)$ & $510(40.9)$ & & \\
\hline High (sum score $\geq 1$ ) & 944 (71.4) & $738(59.1)$ & & \\
\hline Social contact & & & 189.145 & 0.000 \\
\hline Low (less than once a week) & $563(42.6)$ & 868 (69.6) & & \\
\hline High (at least once a week) & 759 (57.4) & $380(30.4)$ & & \\
\hline Depression & & & 13.225 & 0.000 \\
\hline No depression $(0-10)$ & 995 (75.3) & $859(68.8)$ & & \\
\hline Mild-to-severe depression (11-30) & $327(24.7)$ & $389(31.2)$ & & \\
\hline
\end{tabular}




\section{Results}

\section{Sample characteristics}

A total of 1378 migrant elderly and 1343 urban elderly participated in the study, of which 1248 (90.6\%), and 1322 (98.4\%) in each group, respectively, were eligible for analysis. Table 1 presents the full descriptive statistics of the study participants. Chi-square tests revealed notable disparities between two elderly groups. The age of the migrant elderly ranged from 60 to 90 years, with the majority $(80.7 \%)$ being aged $60-69$ years. They were significantly younger than local urban elderly $(p=0.000)$. Migrant elderly were more likely than urban elderly to be male $(46.5 \%$ compared with $40.1 \%, p=0.001)$, married (82.6\% compared with $77.6 \%, p=0.000)$, highly educated (57.2\% for junior high school or more, compared with $46.3 \%, p=0.000)$, live with family member $(93.8 \%$ compared with $68.7 \%, p=0.000$ ), and have better physical function (89.0 compared with $81.7, p=0.000$ ). More than $70 \%$ of migrants' annual household income was less than 50,000 RMB Yuan (About 8250 USD at the time of survey), poorer than urban elderly $(p=0.000)$.

In terms of migration, more than half of the migrant elderly $(56.3 \%)$ had moved from urban to urban areas, with the remaining $43.8 \%$ having moved from rural to urban areas. About $43 \%$ of the migrant elderly had stayed in Hangzhou for less than or equal to 3 years. $44.7 \%$ of migrants came from other provinces, with the other 55.3\% coming from within Zhejiang province. Nearly $87.6 \%$ reported that they had moved to Hangzhou to take care of grandchildren (Table 2).

Table 2 Patterns of migration for migrant elderly

\begin{tabular}{lr}
\hline Variable & $N(\%)$ \\
\hline $\begin{array}{l}\text { Household registration } \\
\text { Urban }\end{array}$ & $702(56.3)$ \\
Rural & $546(43.8)$ \\
Hometown & \\
Zhejiang province & $690(55.3)$ \\
Other province & $558(44.7)$ \\
Length of staying in Hangzhou (years) & \\
$\leq 3$ & $537(43.0)$ \\
$>3$ and $\leq 6$ & $370(29.6)$ \\
$>6$ & $341(27.3)$ \\
Reason of moving to Hangzhou & \\
Taking care of child & $628(52.6)$ \\
Taking care of grandchildren & $1045(87.6)$ \\
Relying on child & $160(13.4)$ \\
Working & $34(2.8)$ \\
Other & $23(1.9)$ \\
\hline
\end{tabular}

\section{Social capital}

Compared with urban elderly, a significantly more migrant elderly reported lower generalized trust $(73.0$ vs. $69.0 \%$, $p=0.025)$, lower reciprocity ( 48.8 vs. $43.3 \%, p=0.005$ ), lower support from individual ( 40.9 vs. $28.6 \%, p=0.000)$ and lower social contact $(69.6$ vs. $42.6 \%, p=0000)$ (Table 1). After adjusting for sex, age, annual household income, education level, marital status, living arrangement, religion faith and physical function, migrant elderly still reported significantly lower levels of generalized trust $[\mathrm{OR}=1.34, \quad 95 \% \quad$ CI $\quad(1.10-1.64)], \quad$ reciprocity [OR $=1.55,95 \% \mathrm{CI}(1.29-1.87)]$, support from individual $[\mathrm{OR}=1.96,95 \% \mathrm{CI}(1.61-2.38)]$, and social contact $[\mathrm{OR}=3.27,95 \%$ CI (2.70-3.97) (Table 3).

Compared with urban-to-urban migrant elderly, rural-tourban migrant elderly demonstrated lower reciprocity ( 54.8 vs. $44.2 \%, p=0.000)$, lower support from individual (45.2 vs. $37.5 \%, p=0.006)$ and lower social contact (74.2 vs. $66.0 \%, p=0002)$, with no significant difference reported in generalized trust (Table 4). After adjusting for sex and age, rural-to-urban migrant elderly were still significantly more likely to have low reciprocity [OR $=1.59,95 \% \mathrm{CI}$ (1.26-1.99)], low support from individual $[\mathrm{OR}=1.49$, $95 \%$ CI (1.18-1.88)], and low social contact $[\mathrm{OR}=1.50$, 95\% CI (1.17-1.93)].

\section{Depression}

The prevalence of depressive symptoms was $31.2 \%$ in migrant elderly and $24.7 \%$ in urban elderly $\left(\chi^{2}=13.225\right.$, $p=0.000$ ) (Table 1). Results of logistic regressions on depression are presented in Table 5. In the crude model, which adjusted for age and sex only, migrant elderly demonstrated higher depression levels than urban elderly $[\mathrm{OR}=1.78,95 \%$ CI (1.47-2.15)]. However, in the fully adjusted Model 3, the effect of migration was attenuated from 2.11 to 1.85 by the inclusion of social capital indicators in Model 2, suggesting that in a small part, some depression disadvantage was caused by lower cognitive social capital (generalized trust and reciprocity) rather than structure social capital (support from individual and social contact). Being younger, married, having higher educational level, higher annual household income and better physical function were also associated with better psychological health.

The prevalence of depression was $27.8 \%$ in urban-tourban migrant elderly and $35.5 \%$ in rural-to-urban migrant elderly $\left(\chi^{2}=8.606, p=0.003\right)$ (Table 4$)$. After adjusting for sex and age, rural-to-urban migrant elderly were still more likely to have higher depression $[\mathrm{OR}=1.63,95 \% \mathrm{CI}$ (1.27-2.10)]. 
Table 3 Odd ratios (OR) with 95\% confidence intervals (CI) of poor social capital indicators

\begin{tabular}{|c|c|c|c|c|c|c|c|c|}
\hline \multirow[t]{2}{*}{ Variable } & \multicolumn{2}{|l|}{ Generalized trust } & \multicolumn{2}{|l|}{ Reciprocity } & \multicolumn{2}{|c|}{ Support from individual } & \multicolumn{2}{|l|}{ Social contact } \\
\hline & OR $(95 \% \mathrm{CI})$ & $p$ & OR $(95 \% \mathrm{CI})$ & $p$ & OR $(95 \% \mathrm{CI})$ & $p$ & OR $(95 \% \mathrm{CI})$ & $p$ \\
\hline \multicolumn{9}{|l|}{ Migrant status } \\
\hline Urban & 1 & & 1 & & 1 & & 1 & \\
\hline Migrant & $1.34(1.10-1.64)$ & 0.004 & $1.55(1.29-1.87)$ & 0.000 & $1.96(1.61-2.38)$ & 0.000 & $3.27(2.70-3.97)$ & 0.000 \\
\hline \multicolumn{9}{|l|}{ Sex } \\
\hline Female & 1 & & 1 & & 1 & & 1 & \\
\hline Male & $1.32(1.09-1.59)$ & 0.004 & $1.24(1.04-1.47)$ & 0.015 & $1.07(0.90-1.28)$ & 0.437 & $0.71(0.60-0.85)$ & 0.000 \\
\hline \multicolumn{9}{|l|}{ Age } \\
\hline $60-69$ & 1 & & 1 & & 1 & & 1 & \\
\hline $70-79$ & $0.73(0.58-0.91)$ & 0.006 & $1.00(0.81-1.24)$ & 0.999 & $1.34(1.08-1.66)$ & 0.009 & $1.25(1.01-1.56)$ & 0.044 \\
\hline $80-$ & $0.50(0.36-0.70)$ & 0.000 & $0.83(0.60-1.14)$ & 0.251 & $0.96(0.69-1.35)$ & 0.830 & $1.82(1.31-2.51)$ & 0.000 \\
\hline \multicolumn{9}{|c|}{ Annual household income (RMB) } \\
\hline $75,000-$ & 1 & & 1 & & 1 & & 1 & \\
\hline $50,000-74,999$ & $0.93(0.70-1.25)$ & 0.635 & $0.84(0.64-1.11)$ & 0.216 & $0.95(0.72-1.26)$ & 0.740 & $1.59(1.20-2.10)$ & 0.001 \\
\hline $25,000-49,999$ & $0.97(0.72-1.31)$ & 0.853 & $0.83(0.63-1.10)$ & 0.193 & $0.80(0.60-1.07)$ & 0.133 & $0.92(0.69-1.22)$ & 0.553 \\
\hline $0-24,999$ & $0.97(0.70-1.34)$ & 0.832 & $1.06(0.78-1.42)$ & 0.721 & $0.77(0.57-1.05)$ & 0.099 & $0.96(0.71-1.31)$ & 0.806 \\
\hline \multicolumn{9}{|l|}{ Education level } \\
\hline \multicolumn{2}{|c|}{ Senior high school and high 1} & & 1 & & 1 & & 1 & \\
\hline Junior high school & $0.84(0.66-1.07)$ & 0.167 & $0.97(0.77-1.22)$ & 0.777 & $1.24(0.98-1.58)$ & 0.078 & $1.25(0.99-1.59)$ & 0.063 \\
\hline Primary school & $1.18(0.91-1.53)$ & 0.218 & $1.52(1.20-1.93)$ & 0.001 & $1.17(0.91-1.51)$ & 0.213 & $1.21(0.95-1.56)$ & 0.123 \\
\hline Illiteracy & $1.64(1.21-2.23)$ & 0.002 & $2.48(1.88-3.26)$ & 0.000 & $1.60(1.21-2.12)$ & 0.001 & $0.75(0.57-1.00)$ & 0.047 \\
\hline \multicolumn{9}{|l|}{ Marital status } \\
\hline Married & 1 & & 1 & & 1 & & 1 & \\
\hline Widowed & $0.73(0.56-0.96)$ & 0.022 & $0.77(0.60-0.99)$ & 0.045 & $1.22(0.95-1.58)$ & 0.120 & $1.37(1.06-1.78)$ & 0.017 \\
\hline Other & $0.73(0.43-1.22)$ & 0.226 & $1.00(0.62-1.63)$ & 0.998 & $1.59(0.99-2.57)$ & 0.056 & $1.67(0.98-2.85)$ & 0.058 \\
\hline \multicolumn{9}{|l|}{ Living arrangement } \\
\hline \multicolumn{2}{|c|}{ Living with family member 1} & & 1 & & 1 & & 1 & \\
\hline Living alone & $1.51(1.16-1.96)$ & 0.002 & $1.51(1.19-1.90)$ & 0.001 & $1.14(0.90-1.45)$ & 0.276 & $0.54(0.43-0.69)$ & 0.000 \\
\hline \multicolumn{9}{|l|}{ Religious faith } \\
\hline Having & 1 & & 1 & & 1 & & 1 & \\
\hline Not having & $1.01(0.82-1.23)$ & 0.962 & $1.09(0.91-1.31)$ & 0.364 & $1.05(0.87-1.28)$ & 0.587 & $0.86(0.71-1.04)$ & 0.129 \\
\hline Physical function & $0.99(0.98-0.99)$ & 0.000 & $0.99(0.98-0.99)$ & 0.000 & $1.00(1.00-1.01)$ & 0.451 & $1.00(1.00-1.01)$ & 0.646 \\
\hline
\end{tabular}

\section{Discussion}

\section{Summary}

To the best of our knowledge, this is the first study to evaluate the relationships among migration and depression and social capital among elderly in China. Our study showed that after controlling for the confounding factors, migrant elderly are more likely to have lower social capital and higher depression compared with urban elderly in Hangzhou where they had immigrated, and rural-to-urban migrant elderly have worse social capital and depression than urban-to-urban migrant elderly. Moreover, the relationship between migration and depression is mediated by cognitive social capital (trust and reciprocity).

\section{Contribution to existing literature}

First, the characteristics of old migrants may reflect the migration selectivity of Chinese older adults. Majority of them migrate to look after grandchildren, which is a prevalent phenomenon in the modern Chinese society. In many other countries, older migrants tend to migrate for better medical care, being nearer family and friends, or better environment [33]. Besides, people with better educational attainment are more inclined toward migration. One reason is that high-educated people know more about the outside world and have a greater interest in gaining experience of it [3]. The other one is that rural people, especially those with lower education, are more influenced by the traditional cultural belief that one should die in the 
Table 4 Social capital and depression of rural-to-urban and urban-to-urban migrant elderly $N(\%)$

\begin{tabular}{|c|c|c|c|c|}
\hline Variable & Urban-to-urban migrant elderly $(N=702)$ & Rural-to-urban migrant elderly $(N=546)$ & $\chi^{2}$ or $t$ & $p$ \\
\hline \multicolumn{5}{|l|}{ Generalized trust } \\
\hline Low & $509(72.5)$ & 402 (73.6) & 0.195 & 0.659 \\
\hline High & $193(27.5)$ & $144(26.4)$ & & \\
\hline Reciprocity & & & 13.818 & 0.000 \\
\hline Low (less than the mean) & $310(44.2)$ & $299(54.8)$ & & \\
\hline High (above the mean) & $392(55.8)$ & $247(45.2)$ & & \\
\hline Support from individual & & & 7.680 & 0.006 \\
\hline Low $($ sum score $=0)$ & $263(37.5)$ & $247(45.2)$ & & \\
\hline High ( sum score $\geq 1$ ) & $439(62.5)$ & $299(54.8)$ & & \\
\hline Social contact & & & 9.802 & 0.002 \\
\hline Low (less than once a week) & $463(66.0)$ & 405 (74.2) & & \\
\hline High (at least once a week) & $239(34.0)$ & $141(25.8)$ & & \\
\hline Depression & & & 8.606 & 0.003 \\
\hline No depression $(0-10)$ & $507(72.2)$ & $352(64.5)$ & & \\
\hline Mild-to-severe depression $(11-30)$ & $195(27.8)$ & $194(35.5)$ & & \\
\hline
\end{tabular}

place where they were born, while urban or well-educated residents are less such affected [34].

Second, this study demonstrated that migrant elderly possess less social capital compared with urban elderly. Emigration to a new place results in loss of network and social interaction from the place of origin. Majority of migrant elderly in our study have short migration duration, which has negative effect on integration and adaptation [35].They may lack resources and infrastructure that can alleviate their acculturation and rebuilt their social network [36]. Furthermore, nearly half of old migrants came from rural areas or other provinces. They would have even poorer capacity to adapt to urban life with new social norms, values, and customs, and overcome cultural barriers such as different dialects, which may reduce the ability to maintain and develop social capital [37]. Besides, stigma against migrants as a common component of social discrimination, which significantly affects social capital reconstruction [38], has been documented in many studies [39, 40].

Third, the finding of more depression among migrant elderly is in keeping with studies from recent meta-analytic review [41], Shenzhen [11] and Beijing [42]. In contrast, studies in Guangzhou [43] and Hangzhou [44] found migrant workers had better mental wellbeing than local urban counterparts had. Besides, some studies, such as the ones in Beijing [45] and Peru [46], showed similar level of mental health in the two groups.

There might be several possible explanations for higher rate of depression among migration elderly in this study. First, the majority of them spent much time looking after grandchildren and doing housework, describing themselves as free nannies. Their adult children are usually busy at work and have little time accompanying and talking with their migrant elderly parents. Also, it is likely to have a conflict with adult children on how to raise grandchildren and on different lifestyle. Lacking emotional support from adult children and the proneness of family conflict are associated with higher risk for depression [47, 48]. Second, with the reduction of family size and the weakening of family function, non family-based network and resources become more important for the elderly. The lack of social support from friends in the original place is positively associated with depression among Chinese elderly [48, 49]. Third, health inequalities may stem from difficulties in accessing resources, as migrants have demonstrated restricted access to health services and social welfare $[50,51]$. While efforts to address health disparities, such as the occurrence of a new health insurance system, are underway in China, existing services and programs have not been fully utilized by migrants yet.

Finally, our results support the finding that cognitive social capital is more important than structural social capital as protective factors of depression. Within psychological health studies, cognitive social capital, i.e., trust and reciprocity, seems to have a stronger impact on health than structural aspects [21, 52, 53]. While the structural aspects [54] provide support through formal and informal institutions, cognitive social capital may increase sense of belongingness within and between communities, which would be beneficial, particularly with regard to mental health.

In view of the massive numbers of migrant elderly in China, this problem is rather alarming and warrants close attention from the Chinese authorities. More social services should be provided to create a friendly community 
Table 5 Odd ratios (OR) with $95 \%$ confidence intervals (CI) of poor depression for elderly

\begin{tabular}{|c|c|c|c|c|c|c|}
\hline \multirow[t]{2}{*}{ Variable } & \multicolumn{2}{|l|}{ Model 1} & \multicolumn{2}{|l|}{ Model 2} & \multicolumn{2}{|l|}{ Model 3} \\
\hline & OR $(95 \% \mathrm{CI})$ & $p$ & OR $(95 \% \mathrm{CI})$ & $p$ & OR $(95 \% \mathrm{CI})$ & $p$ \\
\hline \multicolumn{7}{|l|}{ Migrant status } \\
\hline Urban & 1 & & 1 & & 1 & \\
\hline Migrant & $1.78(1.47-2.15)$ & 0.000 & $2.11(1.68-2.65)$ & 0.000 & $1.85(1.44-2.36)$ & 0.000 \\
\hline \multicolumn{7}{|l|}{ Sex } \\
\hline Female & 1 & & 1 & & 1 & \\
\hline Male & $0.97(0.81-1.16)$ & 0.721 & $1.23(1.01-1.50)$ & 0.040 & $1.14(0.93-1.40)$ & 0.208 \\
\hline \multicolumn{7}{|l|}{ Age } \\
\hline $60-69$ & 1 & & 1 & & 1 & \\
\hline $70-79$ & $2.10(1.69-2.60)$ & 0.000 & $1.50(1.18-1.90)$ & 0.001 & $1.55(1.21-1.99)$ & 0.001 \\
\hline $80-$ & $3.08(2.29-4.13)$ & 0.000 & $1.24(0.87-1.76)$ & 0.229 & $1.42(0.98-2.05)$ & 0.062 \\
\hline \multicolumn{7}{|l|}{ Annual household income (RMB) } \\
\hline $75,000-$ & & & 1 & & 1 & \\
\hline $50,000-74,999$ & & & $1.12(0.79-1.59)$ & 0.528 & $1.17(0.81-1.68)$ & 0.397 \\
\hline $25,000-49,999$ & & & $1.32(0.94-1.86)$ & 0.107 & $1.40(0.99-2.00)$ & 0.060 \\
\hline 0-24999 & & & $1.49(1.04-2.14)$ & 0.029 & $1.54(1.06-2.22)$ & 0.024 \\
\hline \multicolumn{7}{|l|}{ Education level } \\
\hline Senior high school and high & & & 1 & & 1 & \\
\hline Junior high school & & & $0.90(0.67-1.20)$ & 0.462 & $0.92(0.68-1.24)$ & 0.571 \\
\hline Primary school & & & $1.51(1.14-2.00)$ & 0.004 & $1.40(1.04-1.88)$ & 0.026 \\
\hline Illiteracy & & & $2.42(1.77-3.30)$ & 0.000 & $1.98(1.43-2.73)$ & 0.000 \\
\hline Marital status & & & 1 & & 1 & \\
\hline Married & & & 1 & & 1 & \\
\hline Widowed & & & $1.35(1.03-1.76)$ & 0.031 & $1.51(1.14-2.00)$ & 0.004 \\
\hline Other & & & $2.09(1.26-3.46)$ & 0.004 & $2.24(1.30-3.86)$ & 0.004 \\
\hline \multicolumn{7}{|l|}{ Living arrangement } \\
\hline Living with family member & & & 1 & & 1 & \\
\hline Living alone & & & $1.04(0.80-1.36)$ & 0.774 & $0.88(0.67-1.16)$ & 0.366 \\
\hline \multicolumn{7}{|l|}{ Religious faith } \\
\hline Having & & & 1 & & 1 & \\
\hline Not having & & & $0.91(0.73-1.12)$ & 0.372 & $0.91(0.73-1.13)$ & 0.383 \\
\hline Physical function & & & $0.97(0.97-0.98)$ & 0.000 & $0.98(0.97-0.98)$ & 0.000 \\
\hline \multicolumn{7}{|l|}{ Generalized trust } \\
\hline High & & & & & 1 & \\
\hline Low & & & & & $2.14(1.65-2.76)$ & 0.000 \\
\hline \multicolumn{7}{|l|}{ Reciprocity } \\
\hline High & & & & & 1 & \\
\hline Low & & & & & $2.46(2.00-3.03)$ & 0.000 \\
\hline \multicolumn{7}{|l|}{ Support from individual } \\
\hline High & & & & & 1 & \\
\hline Low & & & & & $1.19(0.97-1.47)$ & 0.103 \\
\hline \multicolumn{7}{|l|}{ Social contact } \\
\hline High & & & & & 1 & \\
\hline Low & & & & & $0.99(0.80-1.23)$ & 0.930 \\
\hline
\end{tabular}

environment, which can not only reduce urban-rural barriers, but also help migrant elderly rebuild social capital quickly, thereby improving the wellbeing. Besides, related childcare policy can be proposed to support young families, prevent some involuntary migration happening and relieve the migrant elderly's pressure on childcare. 


\section{Strengths and limitations}

The current study has several limitations. First, the crosssectional study was unable to infer any causal relationship between migration, depression, and social capital. Future longitudinal research should be designed to help further understand any causation. Second, our comparison group only included urban elderly at the place of destination; the rural elderly from the place of origin would provide a further and worthwhile comparison group. Third, this study only discussed social capital at an individual level. Future studies might add community level social capital. Last, while the sample size is large, it is taken from a relatively affluent large city in eastern China, where migrant elderly may enjoy relatively high living conditions and life satisfaction. Thus, it is not supposed to extrapolate the findings to the whole country.

\section{Conclusions}

Our study suggests that migrant elderly might experience higher prevalence of depression and lower level of social capital than urban elderly groups. The depression disadvantage is partly accounted for by lower level of cognitive social capital (trust and reciprocity). In view of the dynamic characteristics of migration, longitudinal studies with representative samples are needed to help us better understand the etiology of mental health problem and changing process of social capital among Chinese migrant elderly.

Acknowledgements This study was funded by the program of the National Natural Science Foundation of China [grant number 71273229]; Zhejiang Natural Science Foundation [grant number LQ12G03015].

Authors' contributions The research was led by Li L. Zhou XD codesigned and co-conducted this study; Li QJ, Jiang MM and Ma S conducted the data analysis; and Li QJ also drafted and revised the manuscript. All the authors have read and approved the final manuscript.

\section{Compliance with ethical standards}

Conflict of interest The authors declare that they have no competing interests.

Open Access This article is distributed under the terms of the Creative Commons Attribution 4.0 International License (http://creative commons.org/licenses/by/4.0/), which permits unrestricted use, distribution, and reproduction in any medium, provided you give appropriate credit to the original author(s) and the source, provide a link to the Creative Commons license, and indicate if changes were made.

\section{References}

1. Lu B (2016) The migrant elderly committed suicide after settling down in Nanjing city with her child. WWW.XHBY.NET. http://js. xhby.net/system/2016/03/22/028173937.shtml. Accessed 22 March 2016
2. Sheng Y (2013) Family migration in China. Popul Res 37(4):66-79

3. Liu Y (2014) An empirical study on the characteristics and impact of the migration of the elderly population in China. Dissertation, Capital University of Economics and Business

4. Meng X, Jiang X, Song J, Wan H, Chen Y, Han Z, He Y (2004) Analysis on the demographic characteristics and related causes of migrant elderly in Beijing. Popul Res 28(06):53-59. doi:10.3969/ j.issn.1000-6087.2004.06.010

5. Zhao Y (1999) Leaving the countryside: rural-to-urban migration decisions in China. Am Econ Rev 89(2):281-286. doi:10.1257/aer.89. 2.281

6. Giles J, Mu R (2006) Elder parent health and the migration decision of adult children: evidence from rural China. Demography 44(2):265-288. doi:10.1353/dem.2007.0010

7. Christiansen F (1990) Social division and peasant mobility in mainland China: the implications of the hu-k'ou system. Issues Stud 26(4):23-42

8. Reifler BV (2006) Play it again, Sam-depression is recurring. N Engl J Med 354(11):1189-1190. doi:10.1056/NEJMe058325

9. Steffens DC, Otey E, Alexopoulos GS, Butters MA, Cuthbert B, Ganguli M, Geda YE, Hendrie HC, Krishnan RR, Kumar A (2006) Perspectives on depression, mild cognitive impairment, and cognitive decline. Arch Gen Psychiatry 63(2):130-138. doi:10.1001/archpsyc.63.2.130

10. Bhugra D (2004) Migration and mental health. Acta Psychiatr Scand 109(4):243-258. doi:10.1046/j.0001-690X.2003.00246.X

11. Shen Q, Lu Y, Hu C, Deng X, Gao H, Huang X, Niu E (1998) A preliminary study of the mental health of young migrant workers in Shenzhen. Psychiatry Clin Neurosci 52(S6):S370-S373. doi:10.1111/j.1440-1819.1998.tb03272.x

12. Li X, Stanton B, Fang X, Xiong Q, Yu S, Lin D, Hong Y, Zhang L, Chen X, Wang B (2009) Mental health symptoms among ruralto-urban migrants in China: a comparison with their urban and rural counterparts. World Health Popul 11(1):24-38. doi:10. 12927/whp.2009.20868

13. Chen L, Li W, He J, Wu LJ, Yan Z, Tang W (2012) Mental health, duration of unemployment, and coping strategy: a crosssectional study of unemployed migrant workers in eastern china during the economic crisis. BMC Publ Health 12:597. doi:10. 1186/1471-2458-12-597

14. Mao Z, Zhao X (2012) The effects of social connections on selfrated physical and mental health among internal migrant and local adolescents in Shanghai, China. BMC Publ Health 12:97. doi:10.1186/1471-2458-12-97

15. Adhikari R, Jampaklay A, Chamratrithirong A (2011) Impact of children's migration on health and health care-seeking behavior of elderly left behind. BMC Publ Health 11(1):143. doi:10.1186/ 1471-2458-11-143

16. Giles J, Wang D, Zhao C (2011) Can China's rural elderly count on support from adult children? Implications of rural-to-urban migration. J Popul Ageing 3:183-204. doi:10.1007/s12062-011-9036-6

17. Knodel J, Saengtienchai C (2007) Rural parents with urban children: social and economic implications of migration for the rural elderly in Thailand. Popul Space Place 13(3):193-210. doi:10.1002/psp.436

18. Zhou H (2002) The migrant elderly with inter provincial migration in China. Chin Popul Sci 02:35-41. doi:10.3969/j.issn.10007881.2002.02.006

19. Zhang Y, Zhou S (2013) Migration selectivity of Chinese migrant eldelry. South China Popul 28(3):38-45. doi:10.3969/j.issn.10041613.2013.03.005

20. Li S (2011) Study on the influence factors for migrant elderly social adaptation. Chin J Gerontol 31(12):2301-2303. doi:10. 3969/j.issn.1005-9202.2011.12.064 
21. Yip W, Subramanian SV, Mitchell A, Lee DTS, Wang J, Kawachi I (2007) Does social capital enhance health and wellbeing? Evidence from rural China. Soc Sci Med 64(1):35-49. doi:10.1016/j.socscimed.2006.08.027

22. Norstrand JA, Xu Q (2012) Social capital and health outcomes among older adults in China: the urban-rural dimension. Gerontologist 52(3):325-334. doi:10.1093/geront/gnr072

23. Shen Y, Yeatts DE, Cai T, Yang PQ, Cready CM (2014) Social capital and self-rated health among middle-aged and older adults in China a multilevel analysis. Res Aging 36(4):497-521. doi:10. $1177 / 0164027513505624$

24. Cao W, Li L, Zhou X, Zhou C (2015) Social capital and depression: evidence from urban elderly in China. Aging Mental Health 19(5):418-429. doi:10.1080/13607863.2014.948805

25. Lesage JP, Ha CL (2012) The impact of migration on social capital: do migrants take their bowling balls with them? Growth Change 43(1):1-26. doi:10.1111/j.1468-2257.2011.00575.x

26. Cheong PH (2006) Communication context, social cohesion and social capital building among hispanic immigrant families. Community, Work Fam 9(3):367-387. doi:10.1080/13668800600743495

27. Zhang L, Wang H, Wang L, Hsiao WC (2006) Social capital and farmer's willingness-to-join a newly established communitybased health insurance in rural China. Health Policy 76(2):233-242. doi:10.1016/j.healthpol.2005.06.001

28. Grootaert C, Narayan D, Jones VN, Woolcock M (2004) Measuring social capital: an integrated questionnaire. World Bank Publications, Washington

29. Yesavage JA, Brink TL, Rose TL, Lum OL, Huang V, Adey M, Leirer VO (1982) Development and validation of a geriatric depression screening scale: a preliminary report. J Psychiatr Res 17(1):37-49. doi:10.1016/0022-3956(82)90033-4

30. Chan AC (1996) Clinical validation of the geriatric depression scale (GDS) Chinese version. J Aging Health 8(2):238-253. doi:10.1177/089826439600800205

31. Mui AC (1996) Geriatric depression scale as a community screening instrument for elderly Chinese immigrants. Int Psychogeriatr 8(3):445-448. doi:10.1017/S1041610296002803

32. Brink TL, Md JAY, Md OL, Md PH, Ba MA, Rose TL (2008) Screening tests for geriatric depression. Clin Gerontol 1(1):37-43. doi:10.1300/J018v01n01_06

33. Rogers A, Frey WH, Rees P, Speare A, Warnes A (1992) Elderly migration and population redistribution: a comparative study. Belhaven Press, London

34. Dou X, Liu Y (2015) Elderly migration in china: types, patterns, and determinants. J Appl Gerontol. doi:10.1177/0733464815587966

35. Wang WW, Fan CC (2012) Migrant workers' integration in urban China: experiences in employment, social adaptation, and selfidentity. Eurasian Geogr Econ 53(6):731-749. doi:10.2747/15397216.53.6.731

36. Kim BJ, Sangalang CC, Kihl T (2012) Effects of acculturation and social network support on depression among elderly Korean immigrants. Aging Mental Health 16(6):787-794. doi:10.1080/ 13607863.2012 .660622

37. Cai X, Cai H (2008) Characterstic and reconstruction of social capital among rural-to-urban migrant workers. Rural Econ 06:107-109

38. Chen X, Stanton B, Kaljee LM, Fang X, Xiong Q, Lin D, Zhang L, Li X (2011) Social stigma, social capital reconstruction and rural migrants in urban China: a population health perspective. Hum Organ 70(1):22-32. doi:10.17730/humo.70.1.k76047734m703500

39. Li X, Zhang L, Fang X, Xiong Q, Chen X, Lin D, Mathur A, Stanton B (2008) Stigmatization experienced by rural-to-urban migrant workers in China: findings from a qualitative study. World Health Popul 9(4):29-43. doi:10.12927/whp.2007.19515
40. Hatch SL, Gazard B, Williams DR, Frissa S, Goodwin L, Hotopf M, Team SS (2016) Discrimination and common mental disorder among migrant and ethnic groups: findings from a South East London Community sample. Soc Psychiatry Psychiatr Epidemiol 51(5):689-701. doi:10.1007/s00127-016-1191-x

41. Zhong BL, Liu TB, Chiu HFK, Chan SSM, Hu CY, Hu XF, Xiang YT, Caine ED (2013) Prevalence of psychological symptoms in contemporary Chinese rural-to-urban migrant workers: an exploratory meta-analysis of observational studies using the SCL90-R. Soc Psychiatry Psychiatr Epidemiol 48(10):1569-1581. doi:10.1007/s00127-013-0672-4

42. Li XM, Stanton B, Fang XY, Xiong Q, Yu SL, Lin DH, Hong Y, Zhang LY, Chen XG, Wang B (2009) Mental health symptoms among rural-to-urban migrants in China: a comparison with their urban and rural counterparts. World Health Popul 11(1):24-38. doi: $10.12927 /$ whp. 2009.20868

43. Li J, Chang SS, Yip PSF, Li J, Jordan LP, Tang Y, Hao Y, Huang $X$, Yang N, Chen C (2014) Mental wellbeing amongst younger and older migrant workers in comparison to their urban counterparts in Guangzhou city, China: a cross-sectional study. BMC Publ Health 14(1):1280. doi:10.1186/1471-2458-14-1280

44. Li L, Wang HM, Ye XJ, Jiang MM, Lou QY, Hesketh T (2007) The mental health status of Chinese rural-urban migrant workers. Comparison with permanent urban and rural dwellers. Soc Psychiatry Psychiatr Epidemiol 42(9):716-722. doi:10.1007/s00127-007-02210

45. Chen $J$ (2011) Internal migration and health: re-examining the healthy migrant phenomenon in China. Soc Sci Med 72(8):1294-1301. doi:10.1016/j.socscimed.2011.02.016

46. De Mola CL, Stanojevic S, Ruiz P, Gilman RH, Smeeth L, Miranda JJ (2011) The effect of rural-to-urban migration on social capital and common mental disorders: PERU MIGRANT study. Soc Psychiatry Psychiatr Epidemiol 47(6):967-973. doi:10.1007/s00127-011-0404-6

47. Lincoln KD, Chae DH (2011) Emotional support, negative interaction and major depressive disorder among African Americans and Caribbean Blacks: findings from the National Survey of American Life. Soc Psychiatry Psychiatr Epidemiol 47(3):361-372. doi:10.1007/s00127-011-0347-y

48. Dong XQ, Chang E, Wong E, Simon M (2011) The perceptions, social determinants, and negative health outcomes associated with Depressive symptoms among US Chinese Older adults. Gerontologist 52(5):650-663. doi:10.1093/geront/gnr126

49. Wang J, Zhao X (2012) Family functioning and social support for older patients with depression in an urban area of Shanghai, China. Arch Gerontol Geriatrics 55(3):574-579. doi:10.1016/j. archger.2012.06.011

50. Li X, Stanton B, Chen X, Hong Y, Fang X, Lin D, Mao R, Wang J (2006) Health indicators and geographic mobility among young rural-to-urban migrants in China. World Health Popul 8(2):5-21. doi:10.12927/whp.2006.18148

51. Peng Y, Chang W, Zhou H, Hu H, Liang W (2010) Factors associated with health-seeking behavior among migrant workers in Beijing, China. BMC Health Serv Res 10:69. doi:10.1186/ 1472-6963-10-69

52. Nyqvist F, Finnas F, Jakobsson G, Koskinen S (2008) The effect of social capital on health: the case of two language groups in Finland. Health Place 14(2):347-360. doi:10.1016/j.healthplace.2007.09.001

53. Phongsavan P, Chey T, Bauman A, Brooks R, Silove D (2006) Social capital, socio-economic status and psychological distress among Australian adults. Soc Sci Med 63(10):2546-2561. doi:10. 1016/j.socscimed.2006.06.021

54. Harpham T, Grant E, Thomas E (2002) Measuring social capital within health surveys: key issues. Health Policy Plan 17(17):106-111. doi:10.1093/heapol/17.1.106 